\title{
The Indigenous Federal Brigades Program in Roraima: From Voluntary Brigades to Official Brigades and FUNAI-RR's Action in this Process
}

Inayê Uliana Perez

National Indigenous Foundation - FUNAI

inaye.perez@funai.gov.br

\begin{abstract}
This article deals with the experience of indigenous brigades in Roraima, where indigenous protagonism is an important factor in the process. Until 2012, PrevFogo/IBAMA in Roraima had only one Indigenous Brigade in Pacaraima, IL São Marcos, and four other non-indigenous. However, there were two volunteer brigades at Indigenous Reserve (IR) Raposa Serra do Sol, where indigenous people were trained by PrevFogo/IBAMA, with support from FUNAI, and there was strong pressure from the indigenous movement to get these brigades hired. Based on discussions around the Technical Cooperation Agreement (TCA) No. 41/2013 between FUNAI and IBAMA for the implementation of Federal Brigades in Indigenous Reserves, there was a closer dialogue between these institutions and indigenous communities, resulting in increased Indigenous Brigades, being installed in 2013 Brigades in four IRs and one in Settlement Project of The National Institute of Colonization and Agrarian Reform (INCRA). The following year, the Settlement Project brigade is dismembered and transferred to the IRs, totaling 6 PrevFogo brigades, all in Indigenous Lands: 2 at Raposa Serra do Sol TI (where before there were voluntary brigades), São Marcos, Araçá, Tabalascada, Serra da Moça. FUNAI-RR, through the Environmental and Territorial Management Service, keep up with the entire hiring process: publicizing the public notice, conducting the tests and since 2013 we have provided eating for all brigade trainings. Eventually we support combat. FUNAI's role in dialogue with communities is extremely important. Our challenge today is to provide a venue for Brigade headquarters. Four are installed in former FUNAI posts, which were extinguished in 2010, the other two work in facilities provided by the community itself, which value the work of the brigades. The brigade program in Roraima has been successful and has shown effective results, mainly through prevention activities focused on Integrated Fire Management (IFM), where interviews were conducted in the indigenous communities on traditional fire use, so that IFM practices can be appropriate to the local environmental and cultural reality. The brigade members, being indigenous, carry their traditional knowledge and use it in daily practices of prevention and combat, combined with the knowledge acquired in IBAMA trainings.
\end{abstract}

Keywords: Indigenous Brigade, Indigenous Lands, Environmental and Territorial Management, Roraima 